\title{
Combatendo o revisionismo: ensino de história da ditadura civil-militar brasileira enquanto disputa de narrativas
}

Fighting Revisionism: History Teaching of the Brazilian Civil-Military Dictatorship as a Dispute of Narratives

Fernando de Lima Nunes*

RESUMO

O presente artigo tem por objetivo trazer ao debate possibilidades de pensar sobre o ensino de história da Ditadura Civil-Militar na educação básica, enquanto um tema sensível, num contexto de amplo revisionismo e negacionismo. Para isso, abordaremos os conceitos e práticas de revisionismo, negação e negacionismo e como isso afeta a memória construída sobre o período da Ditadura Civil-Militar no Brasil. Será debatido também como o conhecimento histórico sobre o período ditatorial mais recente da história brasileira é apreendido pela população, para além da sala de aula. Além disso, será apresentada uma experiência do ensino de História sobre mortos e desaparecidos políticos da Ditadura Civil-Militar a partir dos pressupostos teóricos e metodológicos da Empatia Histórica e seu entrecruzamento com a construção de biografias.

Palavras-chave: ensino de História; ditadura civil-militar; revisionismo.

\section{ABSTRACT}

This article aims to bring to the debate possibilities of thinking about the teaching of the history of the Civil-Military Dictatorship in basic education, as a sensitive topic, in a context of broad revisionism and negationism. For this, we will approach the concepts and practices of revisionism, negation and negationism, and how it affects the memory built on the period of the Civil-Military Dictatorship in Brazil. It will also be debated how historical knowledge about the most recent dictatorial period in Brazilian history is apprehended by the population, beyond the classroom. In addition, an experience of teaching History about the dead and political disappeared during the period of Civil-Military Dictatorship will be presented, based on the theoretical and methodological assumptions of Historical Empathy and their intersection with the construction of biographies.

Keywords: History teaching; civil-military dictatorship; revisionism.

\footnotetext{
* Universidade Federal do Rio Grande do Sul (UFRGS), Porto Alegre, RS, Brasil. limanunes@ gmail.com
} 
O presente artigo tem por objetivo trazer ao debate possibilidades de pensar sobre o ensino de história da Ditadura Civil-Militar na educação básica, enquanto um tema sensível, um passado que não passa, um passado aberto, num contexto de ampla divulgação de explicações revisionistas e negacionistas. Para isso, abordaremos os conceitos e práticas de revisionismo, negação e negacionismo, principalmente a partir de Pereira (2015), e como isso afeta a memória construída sobre o período da Ditadura Civil-Militar no Brasil.

Será debatido também como o conhecimento histórico sobre o período ditatorial mais recente da história brasileira é apreendido pela população, para além da sala de aula, a partir de pesquisas sobre o Ato Institucional número 5.

Como uma possibilidade de combater as fake news e os discursos negacionistas/revisionistas, será apresentada uma experiência do ensino de História sobre mortos e desaparecidos políticos da Ditadura Civil-Militar a partir dos pressupostos teóricos e metodológicos da Empatia Histórica, conforme Peter Lee (2002), e seu entrecruzamento com a construção de biografias.

\section{ENSINO DE HISTÓRIA, MEMÓRIA, REVISIONISMOS E DISPUTAS DE NARRATIVAS}

Trabalhar sobre a história da Ditadura Civil-Militar brasileira em sala de aula traz reflexões complexas, pois permite variados desdobramentos de debates e questionamentos. Esse período da história do Brasil, se encarado como um passado vivo, um tema sensível, uma herança difícil, possibilita a compreensão que ele não é um tema apenas do passado, mas que tem muitas permanências, não só para as vítimas do terrorismo de Estado (PADRÓS, 2014), mas para toda a sociedade que ainda sofre com as heranças desse momento.

Pode-se falar de Ditadura Civil-Militar e discutir questões presentes como punitivismo, prisões arbitrárias, tortura e violência policial. Também podem ser debatidos violência sexual, extermínio de parte da população considerada "indesejada", liberdade de imprensa e vários outros temas. Esses tópicos podem partir do interesse ou vivência dos estudantes. Portanto, mesmo que os alunos e alunas não tenham vivência pessoal ou familiar no período da Ditadura Civil-Militar, eles vivenciam suas heranças.

Entretanto, torna-se cada vez mais presente nas salas de aulas um discurso revisionista ou de negação da violência do Estado durante a Ditadura. Nos 
últimos anos, podemos perceber a proliferação de discursos revisionistas ou negacionistas da História, no Brasil principalmente sobre o período da Ditadura Civil-Militar.

Muitas vezes pensados como sinônimos, revisionismo e negacionismo possuem diferenças entre si. O revisionismo pode ser entendido como uma prática comum na historiografia - revisar as interpretações e análises feitas por outros pesquisadores. Porém, o revisionismo ao qual nos referimos (e que se confunde com o negacionismo) é aquele que faz distorções do passado. Conforme Mateus Pereira, revisionismo é a

interpretação livre que não nega necessariamente os fatos, mas que os instrumentaliza para justificar os combates políticos do presente a fim de construir uma narrativa "alternativa" que, de algum modo, legitima certas dominações e violências. (2015, p. 866)

Por sua vez, a negação seria a

contestação da realidade, fato ou acontecimento que pode levar à dissimulação, à falsificação, à fantasia, à distorção e ao embaralhamento. Em geral, percebemos uma dissimulação e uma distorção da factualidade que, ou procura negar o poder de veto das fontes, ou fabrica uma retórica com base em "provas" imaginárias e/ou discutíveis/manipuladas. (PEREIRA, 2015, p. 865-866)

Portanto, o revisionismo é a prática em que não se nega um fato do passado, mas tenta reinterpretá-lo livremente, geralmente com a intenção de servir de justificativa para ações no presente. A negação, como o próprio termo indica, seria a falsificação do passado, defendendo a não existência de determinado fato ou processo histórico. Para Pereira (2015), o negacionismo seria a radicalização do revisionismo e da negação.

A negação, como dito anteriormente por Pereira, também pode ser feita a partir do veto ao acesso às fontes, inviabilizando uma crítica à interpretação das mesmas. Sobre a importância do acesso às fontes para a História, Koselleck nos diz que

a ciência histórica atual se encontra, portanto, sob duas exigências mutuamente excludentes: fazer afirmações verdadeiras e, apesar disso admitir e considerar a 
relatividade delas. [...] Uma fonte não pode nos dizer nada daquilo que cabe a nós dizer. No entanto, ela nos impede de fazer afirmações que não poderíamos fazer. As fontes têm poder de veto. [...] As fontes nos impedem de cometer erros, mas não nos revelam o que devemos dizer. Aquilo que faz da história história não poderá jamais ser deduzido a partir das fontes. Para que estas finalmente falem, faz-se necessária uma teoria da história possível. (KOSELLECK, 2006, p. 161)

Dessa forma, o acesso às fontes e a disponibilização das mesmas é mais uma das formas de evitar a negação e o revisionismo sobre o passado. A divergência de interpretações das fontes, partindo de diferentes pressupostos teóricos e metodológicos, faz parte da prática de profissionais da História.

No que se referem ao período da Ditadura Civil-Militar, os discursos negacionistas e revisionistas têm origem no próprio regime, com as "versões oficiais" sobre os assassinatos e sequestros cometidos pelo aparato repressivo, por toda a estrutura de desinformação e censura.

Outro momento em que se tentou dominar a narrativa sobre a ditadura foi com a promulgação da Lei 6683/79, a Lei de Anistia. Essa lei serviu para que os militares envolvidos no terrorismo de Estado se defendessem frente à sociedade civil dos crimes cometidos por eles durante a Ditadura Civil-Militar.

A Lei de Anistia tentou, mas não conseguiu, decretar o silêncio sobre esse período da História do Brasil. “A anistia não é capaz de calar, porque não é capaz de fazer esquecer a violação e seus efeitos, não apenas para quem foi por ela vitimado diretamente, mas pela sociedade atingida de inúmeras formas simbólicas" (ROVAI, 2019, p. 94).

Apesar de não decretar o silêncio, a Lei da Anistia dificultou as memórias das vítimas de serem ouvidas por muito tempo, uma vez que a Lei 6683/79 afirmava que o Estado anistiava todos aqueles que tinham cometidos crimes políticos, com a exceção de quem havia cometidos crimes de terrorismo, sequestro, assalto e atentado pessoal. Dessa forma, de maneira intencional, a lei perdoava os torturadores e mantinha os opositores que enfrentaram a ditadura como criminosos.

Portanto, como já dito anteriormente, as disputas pelas narrativas sobre o período da Ditadura Civil-Militar tiveram início no próprio período. No limite, podemos recorrer à ficção escrita por George Orwell, quando projetou 
um futuro num regime totalitário e sua preocupação com a narrativa histórica e o controle sobre essa, ao afirmar que

'Quem controla o passado', dizia o lema do Partido, 'controla o futuro; quem controla o presente, controla o passado. E no entanto o passado, conquanto da natureza alternável, nunca foi alterado. O que agora era verdade era verdade do sempre ao sempre. Era bem simples. Bastava apenas uma série infinda de vitórias sobre a memória. (ORWELL, 1996, p. 36)

Essas disputas sobre a memória (e o passado e a História) não estão presentes apenas na ficção, mas é também um tema bastante presente no nosso cotidiano, sobretudo após a proliferação de discursos revisionistas e/ou de negação nos últimos anos.

O momento em que vivemos hoje, com forte divulgação de fake news e no contexto da pós-verdade, com sua ampla divulgação em redes sociais e aplicativos de comunicação, a revisão e negação da História é muito presente, chegando às salas de aula, muitas vezes como dúvida, outras tantas como tentativa de disputar a narrativa do passado.

O passado, sobretudo o passado de temas sensíveis, está em constante disputa narrativa. Caroline Bauer (2018) levanta questões do que deveria ser levado em conta para refletirmos sobre pesquisas e as diferentes visões acerca da Ditadura Civil-Militar:

aspectos conjunturais, como a época em que a pesquisa [...] foi feita [...]; aspectos culturais, investigando que visões de História as pessoas possuem, como elas se formam e se difundem, e qual a influência dos fenômenos das fake news e a emergência do discurso da pós-verdade nessas compreensões históricas; aspectos educativos, interrogando-se sobre o que tem sido ensinado sobre a ditadura nas escolas e de que forma esse "saber escolar" está confrontando e sendo confrontado pelo aprendizado sobre o tema fora das salas de aula; aspectos geracionais, levando-se em consideração que memória é transmitida para as gerações que não viveram o período; aspectos políticos, analisando a efetividade das políticas de educação para os direitos humanos e as consequências de projetos como o Escola Sem Partido. (BAUER, 2018, p. 196-197)

Para este texto, vamos nos deter principalmente nos aspectos educacionais e culturais, sem, contudo, deixar de pensar nos outros aspectos. Cabe ressaltar 
que as reflexões sobre as narrativas conflitantes sobre a ditadura nas salas de aula são a partir de minhas experiências docentes há mais de 10 anos, atuando no ensino fundamental, ensino médio, educação regular e EJA, escolas públicas e particulares, além de cursos preparatórios para processos vestibulares.

Nesse tempo em que atuo na educação básica, ainda não tive alunos ou alunas que negassem a ditadura. As narrativas conflitantes que chegam na sala de aula têm um caráter menos analítico, e mais apelativo à emoção, a experiências pessoais. Muitas vezes, a revisão é feita na tentativa de justificar algum ato de violência como sendo ou necessário (por ser um confronto contra os "terroristas") ou sendo uma exceção (uma ação individual de uma pessoa que cometeu a violência, e não a existência de um aparato estatal criado para praticar terrorismo de Estado).

Entretanto, o tipo de discurso mais comum que chega dos estudantes é o que legitima as violências cometidas pelo Estado em troca de maior segurança dos "cidadãos de bem". Esse discurso, se confrontado com as pesquisas historiográficas sobre a época não se sustenta, haja visto que foi durante o período da Ditadura em que houve o crescimento do chamado crime organizado. Jovens bicheiros, policiais integrantes de grupos de extermínio e militares oriundos da repressão e da tortura se articulam para estabelecer novos padrões de atuação criminosa (JUPIARA e OTÁVIO, 2015). Ou seja, um discurso comum de quem viveu a época, e, portanto esteve sujeito à desinformação e censura, ainda é bastante comum em jovens que nasceram cerca 20 anos após o fim da Ditadura.

Essas formas de tentar humanizar o período ditatorial brasileiro, usando justificativas carregadas de aspectos emocionais e de experiências individuais, estão de acordo com o que Pereira afirma sobre as tentativas de silenciar ou esquecer o período da Ditadura Civil-Militar:

para se reprimir, silenciar, falsear ou esquecer é preciso contestar a realidade do que se passou durante a Ditadura Militar brasileira não necessariamente pela mentira, mas pela negação e também pelo revisionismo, que distorcem e justificam os crimes e o estado de exceção. Em grande medida são, portanto, discursos e narrativas que justificam práticas, lógicas e ideologias que permanecem e/ou aceitam o inaceitável. (PEREIRA, 2015, p. 877) 
Paul Ricoeur também debate essa problemática das diferentes narrativas quando afirma que "as estratégias do esquecimento enxertam-se diretamente nesse trabalho de configuração; pode-se sempre narrar de outro modo, suprimindo, deslocando as ênfases, refigurando diferentemente os protagonistas da ação assim como os contornos dela" (RICOEUR, 2007, p. 455).

Esses discursos conflitantes e a disputa pela narrativa da Ditadura Civil-Militar foram escancarados com a criação da Comissão Nacional da Verdade, onde grupos e indivíduos favoráveis à Ditadura voltaram a divulgar textos, livros, manifestos sobre o período, escritos em períodos anteriores, como o "Brasil: Sempre", de Marco Pollo Giordani, de 1986; as memórias de Carlos Alberto Brilhante Ustra, de 1987, e de Armando Falcão, de 1989.

Mesmo após o fim de seus trabalhos, a Comissão Nacional da Verdade servia para justificativa de palanque para adoradores do período ditatorial, como por exemplo, Carlos Alberto Augusto, antigo agente do DEOPS-SP e conhecido como Carlinhos Metralha, que em 15 de março de 2015, ${ }^{1}$ saudado por militares da ativa e aplaudido por manifestantes, afirmou ter tirado centenas de fotos com manifestantes com um cartaz "quero ser ouvido pela Omissão da Verdade".

A Comissão Nacional da Verdade foi instituída em maio de 2012 e tinha por finalidade apurar graves violações de Direitos Humanos ocorridas entre 18 de setembro de 1946 e 5 de outubro de 1988. A CNV durou até dezembro de 2014, quando teve lançado seu relatório.

A frase lema da Comissão Nacional da Verdade - "Para que nunca se esqueça, para que nunca mais aconteça" - vem ao encontro da ideia de "dever de memória", discutida por Paul Ricoeur (2007, p. 88) e que pode ser sintetizada como um dever de não esquecer, ou seja, uma reivindicação feita pelas vítimas de uma história criminosa, violenta, traumática, ligando-se, assim, à noção de justiça que devemos às vítimas, acrescida da noção de trabalho de memória.

Um momento de uma história criminosa, violenta e traumática é justamente o período da Ditadura Civil-Militar no Brasil. Pensar o ensino de História sobre esse período nos faz refletir sobre o "dever de memória", pois

assim como ela opera com o holocausto, podemos operar com outras experiências traumáticas, dolorosas e sensíveis - é o caso, por exemplo, da Ditadura 
Militar. Elas nos impõem, inevitavelmente, um dever de memória. Afinal, o desconhecimento e a indiferença de muitos jovens em relação ao que se passou durante a Ditadura Militar brasileira abre espaço para negacionismos, revisionismos e autoritarismos perigosos para a jovem e frágil democracia contemporânea. E são também possibilidades de se identificar com e lutar por diversas estruturas e práticas autoritárias que permanecem e se reinventam constantemente no presente. (PEREIRA e HERMETO, 2016, p. 10)

Além do "dever de memória", segundo Paul Ricoeur, o "trabalho de memória" é outra operação fundamental. O trabalho de memória faz relação com a crítica histórica, o esquecimento, o luto, podendo, ao mesmo tempo, ser uma forma de evitar os excessos do direito de memória. Ou seja, temos o dever de não esquecer, mas com o trabalho de memória, devemos dizer o passado de forma pacífica, por mais doloroso que seja, isto é, se faz necessário incluir a contribuição da crítica historiográfica, não bastando reconhecer e testemunhar o passado.

Partindo desses conceitos, podemos pensar o ensino da história da Ditadura Civil-Militar no Brasil, relacionado à construção das memórias públicas, individuais e coletivas. Isso nos remete à empatia histórica, entendida como uma habilidade de compreender como as escolhas das pessoas do passado estão intimamente ligadas às possibilidades daquele momento, não cabendo julgamentos de nossa parte a partir das possibilidades e conhecimentos do presente (LEE e ASHBY, 2001).

\section{AI-5: USOS POLÍTICOS DO PASSADO}

Refletindo sobre os "aspectos culturais" apontados por Bauer (2018) e a apreensão do passado, as fontes sobre conhecimento histórico ou as informações sobre o passado não são exclusivas das instituições de ensino. É necessário levar em conta, também, a ideia de uso político do passado, desenvolvida por Hartog e Revel (2001) e discutida por Bauer (2017). Muitas vezes, devido ao fato de não serem originadas e organizadas por profissionais da História, causa incompreensões ou entendimentos parciais sobre o passado.

Sobre isso, podemos tomar como exemplo o conhecimento dos brasileiros e das brasileiras sobre o Ato Institucional no 5 (AI-5). Ao analisarmos duas 
pesquisas feitas pelo Datafolha, a primeira em dezembro de $2008^{2}$ e a segunda em dezembro de $2019^{3}$, podemos perceber que o número de brasileiros que ouviram falar sobre o AI-5 aumentou.

Entre os dias 25 e 28 de novembro de 2008, foram ouvidas 3486 pessoas, e o AI-5 era ignorado por $82 \%$ dos entrevistados, sendo que dos $18 \%$ que tinham ouvido falar, apenas um terço respondeu corretamente o que significava a sigla. Ou seja, a enorme minoria dos entrevistados tinha conhecimento sobre o AI-5, não conseguindo, inclusive dizer com precisão o significado da sigla, quanto menos o que representou esse ato.

Por sua vez, nos dias 5 e 6 de dezembro de 2019, foram ouvidas 2948 pessoas em 176 municípios, e, dentre eles, o número de entrevistados que já tinham ouvido falar do AI-5 aumentou. Dentre os entrevistados, $65 \%$ desconheciam o Ato que deu início ao período de maior repressão na Ditadura Civil-Militar no Brasil. Ao compararmos com a pesquisa anterior, a porcentagem das pessoas que já tinham ouvido falar sobre o AI-5 praticamente dobrou em 11 anos.

Além dessas duas pesquisas, na pesquisa Datafolha, realizada com 2016 pessoas em 23 e 24 junho de $2020,{ }^{4}$ o número de brasileiros que tinham conhecimento do AI-5 alcançou 50\%, demonstrando um aumento constante, de $18 \%$ em 2008, 35\% em dezembro de 2019 e 50\% em junho 2020.

Com esses dados, poderíamos inferir que houve um aumento significativo do conhecimento sobre a Ditadura Civil-Militar brasileira. Porém, ao olharmos de perto esse crescimento, chegamos a conclusões diferentes. Esse aumento, em partes, pode ser explicado pela fala do deputado federal e filho do presidente da República Eduardo Bolsonaro, ${ }^{5}$ em outubro de 2019, e do Ministro da Economia Paulo Guedes ${ }^{6}$, em novembro de 2019, justificando a necessidade da Reforma da Previdência e dispostos a fazer o que fosse necessário pra que ela fosse aprovada, falaram na possibilidade de um "novo AI-5". Essas falas foram repercutidas pela mídia tradicional e pelas redes sociais, atingindo um grande número de pessoas.

Portanto, um número maior de pessoas tendo ouvido falar sobre o AI-5 não significa que aumentou a compreensão histórica do período ditatorial brasileiro. Pelo contrário, pois na mesma pesquisa de dezembro de 2019, o apreço pela democracia diminuiu. Em $2018^{8}$, a democracia era vista sempre como melhor que qualquer outra forma de governo por $69 \%$ dos entrevistados. 
Em 2019, esse índice caiu para 62\%. Ao mesmo tempo, cresceu a parcela da população que entende que tanto faz democracia ou ditadura, de $13 \%$ para $22 \%$. A porcentagem dos entrevistados que preferem a ditadura manteve-se estável em $12 \%$.

Assim, não basta ter ouvido falar sobre um período para que se tenha um conhecimento significativo sobre ele. Não basta ter acesso à internet para fazer reflexões sobre o passado e suas relações com o presente e com um futuro desejado. Para isso, torna-se necessária a mediação ou a interação com um profissional da História, nas mais variadas áreas em que se possa atuar.

Ao consultarmos o Google Trends, percebemos que a busca pelo assunto “AI-5" variava entre 1 e 5 em uma escala de 0 a 100 em nível de interesse e popularidade sobre determinado tema. Na semana entre 27 de outubro e 02 de novembro de 2019, logo após a fala do Deputado Eduardo Bolsonaro, o interesse pelo tema sobe para o nível 77, seguido de um pico de 21 na semana entre 24 a 30 de novembro de 2019, pela fala do ministro Paulo Guedes.

O nível 77 de interesse de pesquisa é o segundo maior pico nos últimos cinco anos, ficando atrás apenas da semana entre 19 e 25 de abril de 2020, quando atinge o nível 100. Na ocasião, o presidente Jair Bolsonaro discursou na frente do Quartel General do Exército, em Brasília, para manifestantes que pediam o AI-5. ${ }^{9}$

Podemos perceber, dessa forma, que o deputado e o ministro da economia, fizeram um uso político do passado, evocando a possibilidade deste se repetir no presente, caso fosse necessário.

A atuação dos profissionais da História pode ajudar a compreender não só o passado, mas também os usos que se fazem desse passado no presente. Para tanto, podemos refletir sobre o que a História pode (ou deve) ensinar.

Tomando como exemplo o lema usado pelos familiares de mortos e desaparecidos e por organizações de direitos humanos na América - "para que não se esqueça, para que nunca mais aconteça" - pode-se associar a História como uma disciplina portadora de lições do passado.

No entanto, a ideia dessas lições, as quais não aconteceriam novamente, é problematizada por Caroline Silveira Bauer. Ao refletir sobre o papel da pena nos julgamentos sobre crime lesa humanidade e possível aprendizado com a história, a autora afirma que a teatralidade do processo judicial dá às testemu- 
nhas a possibilidade de inscreverem suas memórias num espaço coletivo. Além disso, a história poderia ter um caráter pedagógico para as gerações futuras. Sobre o primeiro ponto, Bauer defende que

os processos contra crimes lesa humanidade possuiriam uma virtude reparadora, preventiva e pedagógica, que extrapolaria a promulgação de sentenças condenatórias, ao serem investidos de funções catárticas para as vítimas, possibilitado o início da elaboração do luto. (BAUER, 2017, p. 91)

Isto é, mais do que a punição, as vítimas estariam buscando seu reconhecimento como tal, ou seja, recuperando sua autoestima, sua honra e sua reputação. Além disso, esse reconhecimento seria importante não só para a vítima, individualmente, mas para toda a sociedade que de alguma forma sofreu com os regimes ditatoriais.

Sobre o segundo ponto, a autora afirma que

em sociedades nas quais não se assegurou o direito à justiça, valorizou-se sobremaneira a possibilidade de aprendizado com a História, a utilidade do conhecimento histórico como orientação para o futuro ou, ainda, o emprego como matriz para posicionamentos éticos e políticos. (BAUER, 2017, p. 92)

Ainda que, muitas vezes, esse posicionamento ético advenha de uma moral religiosa, tais como o arrependimento ou o pedido de perdão dos algozes das ditaduras, por exemplo.

Assim, no Ensino de História sobre a Ditadura Civil-Militar, podemos problematizar, também, a função (social) da História, visto que a História mestra da vida - evocada em insígnias como "nunca mais" ou "para que não se esqueça, para que nunca mais aconteça" - teve seu sentido questionado há mais de um século. Entretanto, os aprendizados que podemos ter com a História não são da mesma ordem que se esperava com a História mestra da vida. A História tem sim um caráter pedagógico, que faz parte das bases fundamentais da disciplina.

Porém, como trabalhar com a história da Ditadura Civil-Militar afastando-se desse caráter exemplar da História? Talvez, para responder essa questão, devemos pensar a partir do uso político do passado, que, de acordo com Bauer, interpretando Hartog e Revel, costuma "empregar narrativas históricas que 
mobilizam discursos de origens, de fundação ou ruptura, de legitimação e de defesa, sempre evocando um passado - e configurando o uso - demandado pelo presente" (BAUER, 2017, p. 141).

Ou seja, o presente e a sua necessidade de criar uma sociedade dotada de cultura de direitos humanos demanda o uso político do passado do autoritarismo e da violência do Estado brasileiro, diferentemente do que foi feito pelos políticos citados anteriormente, pois esses não buscaram construir uma sociedade baseada nos direitos humanos. Pelo contrário, a busca por uma reforma que privilegia as elites financeiras faz com que o passado seja usado como uma ameaça.

ENSINO DE HISTÓRIA: POSSIBILIDADE

DE COMBATER O REVISIONISMO EM SALA DE AULA

Para Paul Ricoeur, a História tem o privilégio "de corrigir, criticar e até mesmo desmentir a memória de uma comunidade determinada". O autor ainda afirma que "é no caminho da crítica histórica que a memória encontra o sentido de justiça" (RICOEUR, 2007, p. 507). Dessa forma, as aulas de História tornam-se um momento importantíssimo no debate sobre o passado e sua disputa de narrativas.

Uma das possibilidades de combater revisionismo e negação da história da Ditadura Civil-Militar brasileira é trabalhar com a metodologia historiográfica em sala de aula, com estudantes da educação básica. Para isso, a sequência didática que será apresentada aqui, tem como referencial teórico e metodológico a empatia histórica.

A empatia histórica, para Peter Lee, é um dos conceitos que dão consistência ao conhecimento histórico. Esse conceito está ligado ao processo de entender como foi possível que o agente histórico pensasse e sentisse daquela forma. Não buscando ter o mesmo sentimento que ele.

Para Peter Lee, a Empatia histórica pode ser entendida como "algo que acontece quando sabemos o que o agente histórico pensou, quais os seus objetivos, como entenderam aquela situação e se conectamos tudo isso com o que aqueles agentes fizeram" (LEE, 2002, p. 20). Dessa forma, a empatia se dá pela compreensão da intenção dos sujeitos nas ações humanas em outro contexto temporal. 
Pensando em uma definição, Ashby e Lee afirmam que a empatia histórica seria "a capacidade de ver e entender como condicionalmente apropriado, conexões entre intenções, circunstâncias e ações, e de ver como qualquer perspectiva em particular teria realmente afetado ações em circunstâncias específicas" (apud YILMAZ, 2007, p. 332, tradução nossa).

Essas definições demonstram a preocupação de pensar um processo de aprendizagem histórica no qual os estudantes são protagonistas. Em uma sala de aula da educação básica, são os estudantes que constroem seus entendimentos do passado, a partir de práticas que favoreçam a compreensão da História, a mobilização de conceitos historiográficos e a construção de conhecimentos.

Portanto, criar uma sequência didática na qual estudantes tenham a possibilidade de entender e praticar a construção do conhecimento histórico, com rigor teórico e metodológico, pode ser importante para confrontar o crescente revisionismo e a negação da História.

A metodologia adotada para perseguir a questão central dessa investigação foi construída considerando uma série de critérios: contar com uma diversidade de instrumentos que possibilitem o registro e a análise de processos de construção de conhecimento histórico por parte dos estudantes; realizar a investigação em situação cotidiana de aula, sem formar grupos separados ou horários no turno inverso; permitir autoria por parte dos estudantes, mas de forma que conceitos centrais do estudo da Ditadura Civil-Militar sejam mobilizados; dialogar com formas não escolares de texto histórico, como as biografias.

Quando a sequência didática teve início, os alunos já haviam estudado períodos históricos como a Guerra Fria e a Democracia Populista no Brasil, além de conceitos como Terrorismo de Estado, Revolução e Direitos Humanos.

Portanto, no primeiro momento da sequência didática, foi apresentado um conjunto de documentos ${ }^{10}$ históricos impressos de cada personagem ${ }^{11}$ para os alunos, organizados em grupos. Esses documentos foram lidos e analisados pelos alunos, que preencheram uma ficha ${ }^{12}$ disponibilizada pelo professor onde realizaram a análise interna dos documentos.

No segundo momento, com as fichas de análise documentais preenchidas, e com as fontes em mãos, os estudantes iniciaram uma leitura crítica dos documentos, comparando-os com registros historiográficos levados pelo professor. Os alunos também leram textos conceituais e teóricos acerca do período estudado. O professor entregou um resumo-temático acerca da Ditadura Civil-Militar aos alunos. Os estudantes deveriam fazer anotações e apontamentos 
sobre os conceitos estudados sobre as leituras que estavam realizando, que serviu de base para a escrita da biografia.

No terceiro momento, os estudantes, em grupos, realizaram a escrita de uma narrativa biográfica a partir das leituras e análises feitas nas aulas anteriores. Intencionalmente, apresentaram-se modelos de biografias aos estudantes antes dessas etapas, para que eles conhecessem esse gênero. Essa escrita foi orientada pelo professor. No quarto momento, após a entrega dessa escrita e sua leitura pelo professor, as narrativas escritas pelos estudantes foram devolvidas para eles, para que eles pudessem fazer possíveis correções e alterações.

Essa sequência tinha por objetivo desenvolver compreensão de processo histórico e da escrita historiográfica, reconhecendo o passado a partir de leituras das representações produzidas pelas gerações passadas, as circunstâncias do presente e projetos de futuro.

Também fez parte dos objetivos dessa sequência didática ensinar o que Paulo Freire chama de "pensar certo". Para Freire, "o professor que pensa certo deixa transparecer aos educandos que uma das bonitezas de nossa maneira de estar no mundo e com o mundo, como seres históricos, é a capacidade de, intervindo no mundo, conhecer o mundo" (2006, p. 28). Isto é, ensinar a pensar certo só é possível se o professor pensa certo, ou seja, não estar demasiado certo de nossas certezas, estar aberto a novos conhecimentos, não ser um repetidor/memorizador de ideias prontas.

Faz parte do pensar certo "a rejeição mais decidida a qualquer forma de discriminação. A prática preconceituosa de raça, de classe, de gênero ofende a substantividade do ser humano e nega radicalmente a democracia" (FREIRE, 2006, p. 36).

Paulo Freire ainda nos diz que

pensar, por exemplo, que o pensar certo a ser ensinado concomitantemente com o ensino dos conteúdos não é um pensar formalmente anterior ao e desgarrado do fazer certo. Nesse sentido é que ensinar a pensar certo não é uma experiência em que ele - o pensar certo - é tomado em si mesmo e dele se fala ou uma prática que puramente se descreve, mas algo que se faz e que se vive enquanto dele se fala com a força do testemunho. (2006, p. 37)

Isto é, pensar certo e ensinar a pensar certo estão intimamente ligados à crença em uma educação emancipadora, em um ensino colaborativo, em uma 
prática docente crítica. Nesse sentido, pode estar - mas não necessariamente - conectado com o pensar historicamente e com a empatia histórica.

Partindo dessa premissa, a sequência didática foi realizada buscando a construção de conhecimentos significativos pelos estudantes sobre o período da Ditadura Civil-Militar no Brasil a partir da construção das biografias de presos, presas, desaparecidos e desaparecidas políticas.

\section{QUANDO JOVENS ESCREVEM HISTÓRIA}

Nessa parte do artigo está a descrição propriamente dita e a análise $\mathrm{e}^{13} \mathrm{da}$ sequência didática, os problemas e soluções, as continuidades e descontinuidades em relação ao projeto. Além dos questionamentos e resolução de problemas realizados pelos estudantes ao longo do processo. Isto é, como, no desenvolvimento da sequência didática, os estudantes se relacionaram com o tema, com os documentos, com os conceitos, com os colegas e com o professor.

Como dito anteriormente, o referencial teórico e metodológico da sequência didática que será agora apresentada e analisada é a empatia histórica. Cabe aqui salientar que Lee (2002) não entende a empatia como colocar-se no lugar do outro, uma confusão comum em torno do conceito. Além disso, outro ponto controverso é o de que a empatia seria inalcançável, pois o passado não pode voltar, sendo irrecuperável. Realmente, o passado não pode voltar ou ser vivido novamente, mas usando evidências desse passado, podemos inferir sobre ele, descobrindo intenções, compreendendo ações e escolhas feitas em um contexto que não é o nosso.

Dessa forma, a empatia histórica em sala de aula torna-se fundamental, ainda mais em um contexto tão polarizado e recheado de revisionismo e negações, pois conhecendo e reconhecendo o passado, entendendo as razões das escolhas e práticas feitas. Essa é uma das formas de manter uma memória coletiva viva.

Essas experiências têm o potencial de evitar naturalizações ou esquecimentos sobre crimes e violências cometidas no passado. Um dos fatores essenciais para o ensino de História que acredito é reconhecer e compreender a dor do outro, seja esse outro contemporâneo a nós ou não.

Portanto, respeitar não só a dor, mas a existência da diversidade contemporânea ou histórica, isto é, um colega que tem uma religião, raça, identidade 
de gênero, sexualidade diferente da sua, bem como a forma que outras pessoas em outro tempo histórico pensavam, agiam, viviam. Essa diversidade não pode ser menosprezada ou caricaturizada, sendo essa uma das premissas básicas da empatia histórica. Para isso, a construção de um conhecimento histórico escolar a partir da relação dialógica entre estudantes e professor, que tem a responsabilidade a cumprir na formação da cidadania desses estudantes.

No primeiro encontro, os alunos dividiram-se em seis grupos, de acordo com a afinidade e escolha dos próprios estudantes. Após uma orientação geral sobre como organizar e preencher as fichas de análise interna dos documentos, fui a cada um dos seis grupos para explicações e orientações mais específicas, já orientando a coleta de dados para a atividade seguinte, que seria a escrita biográfica.

Durante a análise dos documentos, os estudantes perceberam informações desencontradas, como a grafia dos nomes - Manoel Raymundo ou Manoel Raimundo - ou sobre a ocupação da pessoa - estudante ou professora - no caso de Ísis Dias de Oliveira.

O grupo que pesquisou sobre Flávio de Carvalho Molina ficou bastante confuso com a documentação a ser analisada, pois havia documentos com o nome de Álvaro Lopes Peralta e, por isso, pensaram se tratar de outra pessoa. Depois, lendo outros documentos, o grupo percebeu que era um nome falso que Flávio usou para escapar da vigilância do serviço de inteligência do regime ditatorial brasileiro.

Conforme iam preenchendo a ficha de análise interna, os alunos e as alunas debatiam acerca das informações encontradas. Como, por exemplo, a quantidade de informações sobre a morte de Manoel Raimundo Soares. Sobre esse caso, havia uma série de capas de jornal com notícias explícitas e depoimentos sobre o caso. Um estudante perguntou se aquela quantidade de notícia se devia ao fato de ter sido um caso famoso ou se era porque a pessoa morta era um sargento. Perguntei ao grupo a data desse caso e eles encontraram a data de agosto de 1966 em uma ata da CPI aberta pela Assembleia Legislativa do Rio Grande do Sul.

Solicitei que lessem novamente o resumo temático sobre a Ditadura Civil-Militar que entreguei para a turma na aula anterior e procurassem sobre o AI-5. Assim, esse grupo percebeu que a quantidade de notícias não tinha relação com a vítima, mas sim pelo fato de ter acontecido antes da censura ter sido 
oficializada e estruturada com o AI-5, dois anos após o caso. Convidei os estudantes a circularem pela sala e observarem os documentos dos outros grupos para ver se havia capas de jornal narrando outro desaparecimento. Como os outros crimes ocorreram depois do AI-5, eles não encontraram tais materiais.

Infelizmente, essas reflexões e análises, via de regra, não apareceram nas biografias escritas pelos estudantes. Apesar de terem feito profundos debates acerca dos documentos, conceitos e suas interpretações, muito provavelmente os estudantes pensaram em "dar a resposta certa", ou seja, escrever o texto biográfico de seus personagens com as informações encontradas nos documentos, sem registrar suas interpretações sobre eles. Daí a importância do professor acompanhar todo o processo de ensino e aprendizagem para verificar a construção de conhecimentos pelos estudantes.

Mesmo assim, um grupo questionou se poderiam colocar suas opiniões na biografia. Minha resposta foi que deveriam escrever e se posicionar, corrigindo-os que tudo o que escrevessem não seria uma opinião, mas sim um conhecimento histórico construído por eles baseado em análise de fontes, uso de conceitos e em cruzamento com textos historiográficos.

Um exemplo de grupo que registrou suas interpretações foi o que pesquisou sobre Isis Dias de Oliveira. Esse grupo apresentou um debate sobre o fato dela aparecer em documentos ora como foragida, ora como desaparecida. Com isso, podemos perceber a capacidade dos alunos e das alunas de identificar e interpretar pontos de vista contraditórios do passado, tentando compreender e criar uma visão do presente sobre esse passado. Esse grupo percebeu que, em documentos dos órgãos de segurança, Isis aparecia como foragida, o que segundo os estudantes a colocaria numa condição de criminosa. Perceberam também que em uma carta escrita por sua mãe, Isis era descrita como uma desaparecida, ou seja, como uma vítima. Suas conclusões foram de que ela estava foragida, mas foi presa e, depois, passou a condição de desaparecida, pois seu corpo foi reconhecido e estava registrado em uma ficha com a inscrição "falecidos". Para esse grupo, isso representou um ato de terrorismo de Estado, pois os militares, na condição de representantes do Estado, mataram e esconderam o corpo.

Para Benito Schmidt (2000), existe espaço para a ficção nas narrativas, mesmo em biografias de caráter historiográfico. Para Schmidt, quando o autor da biografia escreve sobre uma possibilidade, ele deve anunciar ao seu leitor a 
partir de expressões como "provavelmente", "talvez", "pode-se presumir". O grupo que pesquisou sobre Isis fez isso na sua narrativa, deixando explícito que aquelas conclusões eram interpretativas, como por exemplo, quando escrevem: "Nossa teoria é de que o "amigo" da família, que prometeu trazer informações (1974), ele atuava no DOPS, logo, sabia do seu paradeiro, que nos arquivos do DOPS ela se encontra falecida, e isso foi tudo armação para criar confusão e esperança na família". ${ }^{14}$

A biografia de Flávio de Carvalho Molina apresenta, em sua maior parte, os debates e análises feitas na narrativa final, bem como interpretações sobre os documentos analisados. As alunas usaram o conceito de terrorismo de Estado de uma maneira que se encaixasse no texto. Quando afirmavam que ele foi torturado até a morte, escreveram que Flávio foi "vítima de terrorismo de Estado, onde o governo o reprimiu por ser contra a ditadura". Em outros momentos em que se pode perceber o terrorismo de Estado, as alunas não fizeram ligação direta com o conceito, como, por exemplo, quando elas escreveram que as ossadas de Flávio estavam enterradas no cemitério de Perus "com o nome falso de Álvaro Lopes Peralta, mesmo o governo sabendo que esse era um nome falso de Flávio".

Elas chegaram a essa conclusão após a leitura da certidão de óbito em nome de Álvaro e de uma ficha de controle de Flávio que constava como um dos nomes falsos usados por ele, justamente o de Álvaro Lopes Peralta. Assim, podemos notar a construção do conhecimento histórico, uma vez que, da análise de duas fontes diferentes do mesmo período histórico, elas chegaram a uma informação que não estava explícita em nenhum documento.

Segundo esse grupo, "Flávio começou a usar identidades falsas para fugir da Ditadura e não ser preso", usava nomes falsos, "tudo para dificultar a busca dele", "Flávio de Carvalho Molina participava de grupos anti-ditadura e por esse motivo foi perseguido e morto pelo governo militar", "a secretaria [de segurança] sabia que Álvaro era Flávio [...]. Eles enterraram com o nome falso pra família não achar".

No que se refere à empatia histórica, as estudantes conseguiram evidenciar que as escolhas de seu personagem estão intimamente ligadas ao contexto em que ele vivia, sobretudo na passagem em que destacam a escolha de Flávio sair da casa dos pais para que a Ditadura não os perseguisse como a ele mesmo, 
como, por exemplo, quando escrevem: "Flávio, em 1969, deixou a casa de seus pais para não transferir a repressão que sofria para sua família”.

Dessa forma, percebemos que uma sequência didática construída com um referencial teórico e metodológico coerentes, possibilita aos estudantes não só aprender sobre o passado, mas problematizar a construção desse passado e produzir narrativas sobre o tempo que está estudando. A empatia histórica é um dos referenciais que abre margem para essas práticas, pois defende o uso crítico de documentos para compreender as possibilidades e intensões dos agentes do passado.

\section{CONSIDERAÇÕES FINAIS}

Pensar em uma aula de história que busque refletir sobre os mortos e desaparecidos políticos da Ditadura Civil-Militar brasileira a partir da construção de biografias por parte de estudantes da educação básica, com base em conceitos, fontes históricas e outros registros historiográficos como uma possibilidade de combater narrativas revisionistas ou de negação foi um desafio para um número reduzido de páginas.

Enquanto professores e professoras de História, temos que ter em mente que os alunos e as alunas já trazem conhecimentos históricos antes de entrarem na aula de História em uma escola. Valorizar e respeitar esse conhecimento sobre o passado, pensando como uma possibilidade de usá-lo a favor da construção de conhecimentos históricos embasados e significativos pode ser um dos objetivos primordiais das aulas de História.

Para isso, pensar o ensino de História numa perspectiva de fronteira, partindo de conceitos históricos e conhecimentos construídos em rede, por vários atores, em múltiplos espaços, torna-se essencial para a construção de conhecimentos que levem em consideração as vivências que saem pelos poros da sociedade e pelos diferentes meios de comunicação.

Dessa forma, pensar a aula de História sobre a Ditadura Civil-Militar como um espaço em que a construção de um conhecimento sensível é potencializado, é pensar em uma aula que possibilite aos estudantes aprender e colocar em prática como o conhecimento histórico é produzido. Podendo, também, problematizar essa produção de conhecimento e os jogos de poder que circulam a distribuição e consumo de determinadas narrativas sobre o passado em detrimento de outras. 
Trabalhar com estudantes enquanto protagonistas do processo de criação de conhecimento é uma possibilidade para entrar na disputa pela narrativa do passado da Ditadura Civil-Militar no Brasil.

Cabe ressaltar, ainda, que no contexto em que vivemos de proliferação e ampla divulgação até mesmo por órgãos do governo de narrativas revisionistas e negacionistas da História de forma geral, e da história da Ditadura Civil-Militar em específico, não basta "não esquecer" ou apenas "lembrar" o que aconteceu nesse período. É necessário refletir, questionar e produzir narrativas sobre esse passado que não passa e que deixou muitas cicatrizes ainda abertas na sociedade brasileira.

Essas reflexões e novas narrativas foram feitas por jovens, num trabalho em relação dialógica com um professor de História preocupado com a criticidade, comprometido com a autonomia, a emancipação, a democracia, os direitos humanos e o potencial pedagógico da História, construídos a partir de uma construção teórico-metodológica e escolhas didáticas que proporcionem uma abordagem problematizadora e respeitosa sobre esse tema sensível.

Esses jovens, dentro de suas capacidades, limites e interesses, contribuíram para a formação de um saber sobre uma questão socialmente relevante. Uma questão viva e presente na vida de muitos jovens que têm uma perspectiva de futuro na qual violência estrutural, ditaduras, tortura e terrorismo de Estado não estejam mais presentes.

Além disso, o conhecimento histórico sobre esses mortos e desaparecidos da Ditadura Civil-Militar brasileira produzido pelos alunos e alunas da educação básica de escolas públicas, com a qualidade que foi realizado, é muito importante pois apresenta um pouco do que é feito nas escolas e nas aulas de História por professores, professoras, alunos e alunas com resultados muito positivos. Portanto, apresentar pesquisas feitas nesses espaços é fundamental nesse contexto de desvalorização do saber, da ciência, do conhecimento, da educação, da História e da educação pública.

\section{REFERÊNCIAS}

BAUER, Caroline Silveira. Como será o passado?: história, historiadores e a Comissão Nacional da Verdade. 1.ed. Jundiaí: Paco, 2017.

BAUER, Caroline Silveira. Qual o papel da história pública frente ao revisionismo histórico? In MAUAD, Ana Maria; SANTHIAGO, Ricardo; BORGES, Viviane Trin- 
dade. Que história pública queremos? What public history do we want?. São Paulo: Letra e Voz, 2018.

FREIRE, Paulo. Pedagogia da Autonomia: saberes necessários à prática educativa. Rio de Janeiro: Paz e Terra, 2006.

HARTOG, François; REVEL, Jacques. Note de conjoncture historiographique. In: HARTOG, François; REVEL, Jacques (eds.). Les usages politiques du passé. Paris: Enquête, 2001.

JUPIARA, Aloy; OTÁVIO, Chico. Os porões da contravenção - jogo do bicho e ditadura militar: a história da aliança que profissionalizou o crime organizado. Rio de Janeiro: Record, 2015.

KOSELLECK, Reinhart. Futuro passado. Rio de Janeiro: Contraponto; PUC-Rio, 2006.

LEE, Peter. Nós fabricamos carros e eles tinham que andar a pé: compreensão das pessoas do passado. In. BARCA, Isabel. Educação histórica e museus. actas das segundas jornadas internacionais de educação histórica. Braga: Lusografe, 2002.

LEE, Peter; ASHBY, Rosalyn. Empathy, perspective taking, and rational understanding. In: Historical empathy and perspective taking in the social studies. Boston: Rowman \& Littlefield publishers, inc, 2001, p. 21-50.

NUNES, Fernando de Lima. Para não esquecer: ensino de história e empatia histórica a partir da escrita de biografias de desaparecidos políticos da ditadura civil-militar brasileira. Dissertação (Mestrado em Ensino de História). Instituto de Filosofia e Ciências Humanas, Universidade Federal do Rio Grande do Sul. Porto Alegre, 2018. Disponível em: https://www.lume.ufrgs.br/handle/10183/185949. Acesso em: 31/01/2021.

ORWELL, George. 1984. São Paulo: Editora Nacional, 1996.

PADRÓS, Enrique. Terrorismo de Estado: reflexões a partir das experiências das DSN. In: GALLO, Carlos Arthur; RUBERT, Silvania. (Orgs.) Entre a memória e o esquecimento. Porto Alegre: Deriva, 2014.

PEREIRA, Mateus Henrique de Faria. "Nova direita? Guerras de memória em tempos de Comissão da Verdade (2012-2014)". Varia Historia, Belo Horizonte, v. 31, n. 57, p. 863-902, 2015.

PEREIRA, Mateus; HERMETO, M. Justa memória, dívida ética e passados-presentes dolorosos: questões a partir da análise de interpretações sobre a ditadura militar brasileira (1964-1985) em livros didáticos de história. In: MAIA, Tatyana de Amaral; ALVES, Luís Alberto Marques; HERMETO, Miriam; RIBEIRO, Cláudia Sofia Pinto. (Orgs.). (Re)construindo o passado: o papel insubstituível do ensino da história. 1.ed. Porto Alegre/BR; Porto/PT: EDIPUCRS-CITCEM, 2016, p. 150-168.

RICOEUR, Paul. A memória, a história, o esquecimento. Campinas: Unicamp, 2007. 
ROVAI, Marta Gouveia de Oliveira. Ensino de história e a história pública: os testemunhos da Comissão Nacional da Verdade em sala de aula. In: Revista História Hoje, v. 8, n.15, p. 89-110, 2019.

SCHMIDT, Benito Bisso. Luz e papel, realidade e imaginação: as biografias na história, no jornalismo, na literatura e no cinema. In: SCHMIDT, Benito Bisso (org). $O$ biográfico: perspectivas interdisciplinares. Santa Cruz do Sul: EDUNISC, 2000.

YILMAZ, Kaya. Historical Empathy and Its Implications for Classroom Practices in Schools. The History Teacher, Long Beach, v. 40, n. 3, p. 331-337, 2007.

\section{NOTAS}

${ }^{1} 15$ de março de 2015, quando aproximadamente um milhão de pessoas foram à ruas pedindo a saída da então presidenta Dilma Rousseff em todo o país. Além dos discursos contra o PT, era possível ouvir gritos pedindo a volta dos militares e o combate ao comunismo. Além das falas de Carlinhos Metralha, frases como "a nossa bandeira jamais será vermelha", "livrai-nos do comunismo", "fora comunismo", "intervenção militar já" estavam escritas em diversos cartazes.

${ }^{2}$ Disponível em: http://www1.folha.uol.com.br/poder/2008/12/478933-oito-em-cada-dez-brasileiros-nunca-ouviram-falar-do-ai-5.shtml. Acesso em: 07/08/2020.

${ }^{3}$ Disponível em: https://www1.folha.uol.com.br/poder/2020/01/dois-tercos-da-populacao-dizem-nunca-ter-ouvido-falar-do-ai-5-aponta-datafolha.shtml. Acesso em: 07/08/2020.

${ }^{4}$ Disponível em: http://datafolha.folha.uol.com.br/opiniaopublica/2020/06/1988776-apoio-a-democracia-atinge-75.shtml. Acesso em: 20/08/2020.

${ }^{5}$ Disponível em: https://www1.folha.uol.com.br/colunas/monicabergamo/2019/10/eduardo-bolsonaro-diz-que-se-esquerda-radicalizar-resposta-pode-ser-um-novo-ai-5.shtml. Acesso em: 08/08/2020.

${ }^{6}$ Disponível em: https://www1.folha.uol.com.br/mercado/2019/11/nao-se-assustem-se-alguem-pedir-o-ai-5-diz-guedes.shtml. Acesso em: 08/08/2020.

${ }^{7}$ Disponível em: https://www1.folha.uol.com.br/poder/2020/01/apoio-a-democracia-cai-no-primeiro-ano-do-governo-bolsonaro-diz-datafolha.shtml. Acesso em: 07/08/2020.

${ }^{8}$ Disponível em: https://www1.folha.uol.com.br/poder/2018/10/democracia-tem-aprovacao-recorde-no-brasil.shtml. Acesso em: 08/08/2020.

${ }^{9}$ Disponível em: https://noticias.uol.com.br/politica/ultimas-noticias/2020/04/19/jair-bolsoanaro-nao-queremos-negociar-nada-manifestacao-anti-congresso.htm. Acesso em: $12 / 08 / 2020$.

${ }^{10}$ A documentação para compor as biografias dos mortos e desaparecidos da Ditadura ci- 
vil-militar foi encontrada no site da Comissão da Verdade do estado de São Paulo, disponível em: https://bit.ly/2RSjvNE.

${ }^{11}$ As personagens escolhidas para a escrita de suas biografias foram: Ísis Dias de Oliveira, Flávio de Carvalho Molina, Alceri Maria Gomes da Silva, David Capistrano da Costa, Luiza Augusta Garlippe e Manoel Raimundo Soares. A escolha desses personagens foi feita de forma a ter diversidade étnico-racial, de gênero e social.

${ }^{12}$ A ficha de análise interna dos documentos contava com as seguintes questões: O que é o documento? Quem é o autor? Quando produziu a fonte? Por que? O que a fonte me diz sobre a personagem? O que a fonte permite inferir sobre a Ditadura Civil-Militar? O que mais a fonte me diz que ajude a escrever a biografia? O que a fonte não me diz e como posso saber mais sobre isso?

${ }^{13}$ Para uma análise mais completa ver NUNES, 2018.

${ }^{14}$ Nesta, como nas seguintes citações diretas dos estudantes, foram corrigidas possíveis faltas ortográficas.

Artigo submetido em 27 de outubro de 2020. Aprovado em 28 de janeiro de 2021. 